\title{
Sensorless control for active damping of torsional vibrations in wind turbine drivetrains with doubly-fed induction generator
}

\author{
Prof. Dr.-Ing. Jan Wenske ${ }^{1}$, Prof. Dr.-Ing. habil. Ulrich Beckert ${ }^{2}$ \\ ${ }^{1}$ Fraunhofer-Institute for Wind Energy und Energy System Technology \\ IWES \\ Am Seedeich 45, 27572 Bremerhaven (Germany) \\ Phone/Fax number:+0049 471 14290-400, e-mail: Jan.Wenske@iwes.fraunhofer.de \\ ${ }^{2}$ Institute for Electrical Engineering, TU Bergakademie Freiberg \\ Bernhard-von-Cotta-Straße 4, 09599 Freiberg (Germany) \\ Phone/Fax number:+0049 3731-392929, e-mail: Ulrich.Beckert@et.tu-freiberg.de
}

\begin{abstract}
.
Until now, the most common drivetrain concept for multimegawatt wind turbines is still the classic design with multi-stage gearbox and fast running doubly-fed induction generator (DFIG). Some control strategies for damping of drivetrain torque oscillations already exist, but they based on mechanical sensors, e.g. speed and rotary encoders which can fail within the harsh environment of a wind turbine. To reach the highest possible system reliability it is obvious trying to minimize the number of installed sensors.
\end{abstract}

This contribution shows an innovative sensorless control method with great performance for DFIG coupled to highly oscillatory mechanical drive systems, such as in wind turbine drivetrains. The aim of the approach is, to reduce wear and increase service life by means of active damping torsional vibrations in the mechanical drivetrain during normal operation using a high reliable sensorless control system for the converter-fed generator. The outstanding feature of the control method is, that it requires no sensors for rotational angle, speed or shaft torque and considers the inherent highly oscillatory characteristic of geared drivetrains mostly equipped with DFIG.

Therefore measuring of electrical quantities, that is the stator phase voltages and currents and rotor phase currents of a DFIG is sufficient, when using a combination of different observer structures for the electrical and mechanical subsystem of the drivetrain. The outcome is a sensorless field oriented vector and a state controller for effective active damping. The presented algorithms are tested on a laboratory test rig, some of the results and measurements are presented here.

\section{Key words}

Doubly-fed induction generator (DFIG), active damping, field oriented vector-control (FOC), sensorless control, Luenberger observer, model reference adaptive system (MRAS)

\section{Introduction}

Today drivetrains utilizing doubly-fed induction generators (DFIG), which represent the cost-effective alternative to inverter-fed synchronous machines, for fully variable rotor speed operation of modern multi megawatt wind turbines. While for the solution with the synchronous machine the entire electrical power flows via the inverter, designed for rated turbine power, the power electronic for the DFIG system, connected to the rotor windings by slip rings, delivers only the apparent power of the DFIG rotor. This electrical power is proportional to the rotor slip and therefore corresponds only to a certain fraction of the total apparent power of the DFIG respectively the wind turbine, if we confine to a narrow operational speed range around the synchronous speed.

Figure 1 shows the required apparent power of the inverter as a function of rotor slip in regenerative operation of the DFIG with rated active power for different values of generated reactive power output.

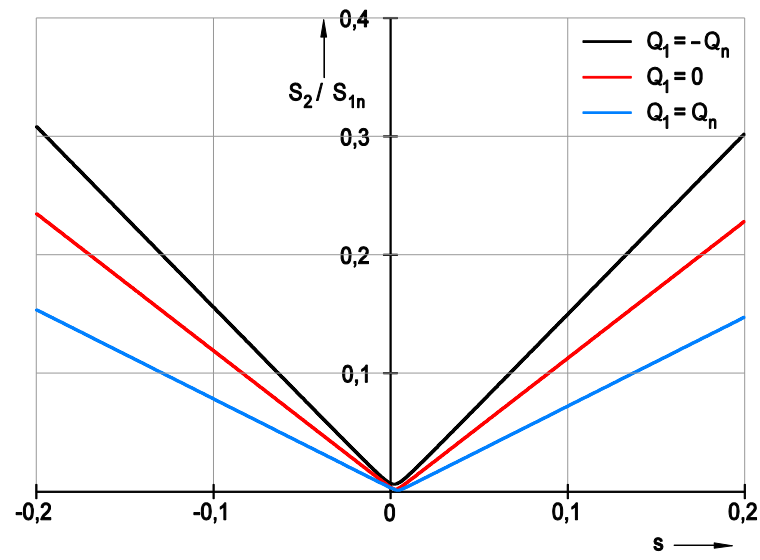

Fig. 1: Converter apparent power as a function of the rotor slip at rated active power of DFIG in generator mode 
Just as solutions with full inverter the DFIG system offers the advantage, that active and reactive power can be controlled, decoupled from the operational speed [1,2], independently of each other. For this purpose a field oriented control (FOC) of rotor currents takes place in the stator flux oriented rotating space vector coordinate system.

The controlled drivetrain of a wind turbine can be roughly divided into an electrical and a mechanical subsystem. The electrical subsystem describes the electromagnetic conversion and the control of the air gap torque by power electronic. The mechanical subsystem is mostly an oscillatory multi mass system, for control engineering purposes it can be sufficiently accurate described by a two-mass rotational oscillator in general, but especially inside wind turbine drivetrains. Its first rotational natural frequency is usually in the range of $3-20 \mathrm{~Hz}$.

In the classic drivetrain control schema using PI-Controller the air gap torque $m_{i}$ is applied according to the setpoint value $m_{i}^{*}$, which is delivered by the speed or active power controller, without any respect on drivetrain oscillatory characteristics.

Changes in the air gap or the load torque, usually caused by the wind rotor or setpoint variations on the generator side, lead to unwanted torsional oscillations and therefore to wear, higher fatigue stress and shorter service life of the components.

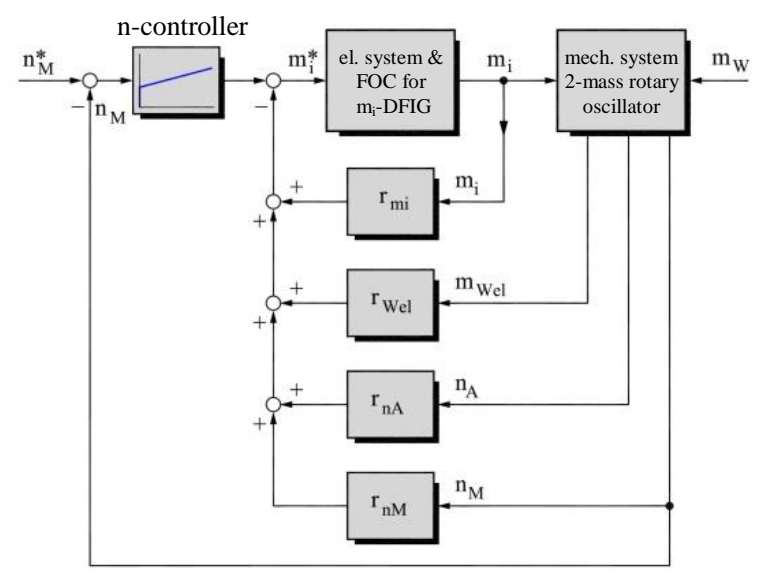

Fig. 2: Vibration damping by means of state controller

By incorporating the mechanical subsystem or at least its dominant oscillation characteristic in the control structure, most effectively by using a state controller according to Figure 2, torsional oscillation within the drivetrain could be actively damped [3] and thus wear reduced. However, for the best results, the instantaneous values of all state variables of the mechanical system $\left(m_{i}, n_{M}, m_{W e l}, n_{A}\right)$ are needed for feedback within a full state control. Since the continuous measurement of all these values during operation is very complex and due to technical and economically reasons will not be tolerated in general, it's proposed here, to reconstruct the necessary state variables by means of a suitably mathematical observer structure.

An estimator system for field oriented AC-drives application including a DFIG and an oscillatory multi mass mechanical system will be presented below. At which the air gap torque and the rotational speed of DFIG, the shaft torque within the drivetrain as well as the load side speed and torque can be estimated during dynamic operation in high quality. This process monitors the stator voltages and stator and rotor currents of DFIG (Figure 3) only.

This state variable estimator for drivetrains with DFIG system consists of a MRAS structure for the DFIG itself and an observer, presented here as deterministic variant (Luenberger), for the mechanical system (Figure 4).

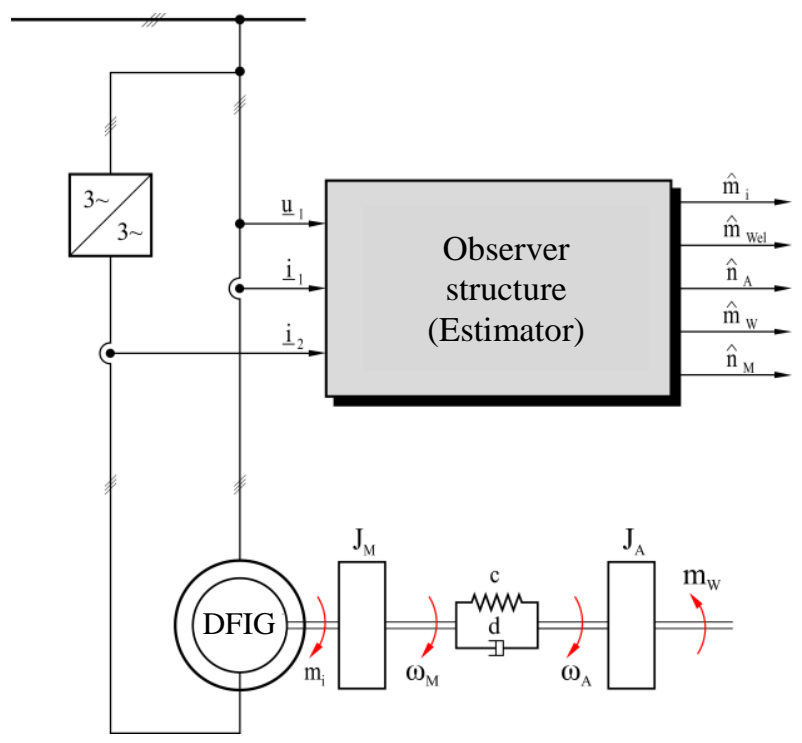

Fig. 3: Observer for drivetrains with DFIG

This novel estimator structure combining the electrical as well as the mechanical system is the key element for a sensorless DFIG control including the active damping functionality for rotary oscillations and corresponding wear reduction.

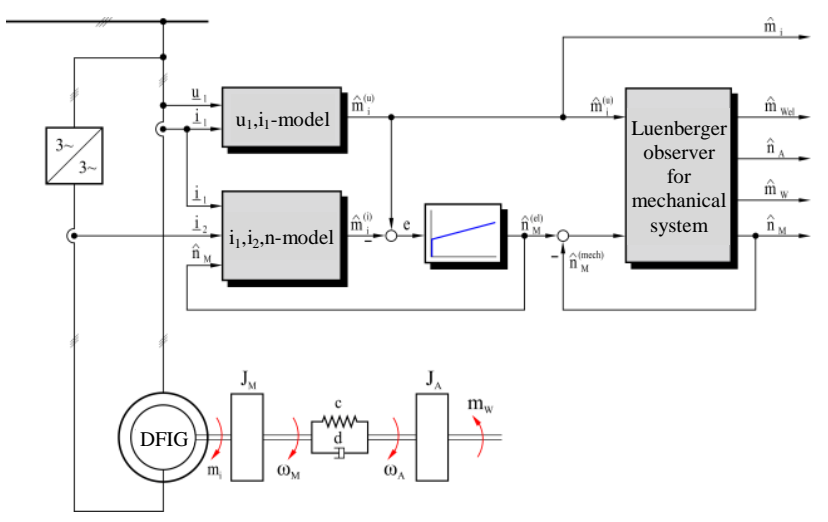

Fig. 4: Complete state variable estimator, divided into electrical subsystem (MRAS) and mech. subsystem (Luenberger observer)

\section{Model of the doubly-fed induction machine}

The proposed estimator algorithms for the air gap torque and the rotational speed of the DFIG based on the wellknown mathematical model for fundamental components and without considering current displacement in the stator related coordinate $(\alpha, j \beta)$-system of induction machines [5]: 


$$
\begin{aligned}
& \frac{d \underline{\psi_{1}}}{d t}=\underline{u}_{1}-R_{1} \underline{i}_{1} \\
& \frac{d \underline{\psi_{2}}}{d t}=\underline{u}_{2}+j n \underline{\psi}_{2}-R_{2} \underline{i}_{2} \\
& \underline{\psi_{1}}=X_{1} \underline{i}_{1}+X_{h} \underline{i}_{2} \quad \underline{\psi_{2}}=X_{h} \underline{i}_{1}+X_{2} \underline{i}_{2} \\
& m_{i}=\underline{\psi}_{1} \times \underline{i}_{1}=\frac{X_{h}}{X_{2}}\left|\underline{\psi_{2}} \times \underline{i_{1}}\right| \\
& \frac{d n}{d t}=\dot{n}=\frac{1}{T_{M}}\left(m_{i}-m_{w}\right)
\end{aligned}
$$

Therein are $\underline{u}_{1}, \underline{u}_{2}$ the space vectors of the stator and rotor voltage, $\underline{\psi}_{1}, \underline{\psi}_{2}$ the space vectors of the stator and rotor flux, $\underline{i}_{1}, \bar{i}_{2}$ the space vectors of the stator and rotor currents, $R_{1}, R_{2}$ the ohmic stator and rotor resistances, $X_{1}, X_{2}$ the stator, rotor and $X_{\mathrm{h}}$ the main reactance.

This system of equations is only valid under the idealized assumptions of a perfectly symmetrical setup of the machine, a sinusoidal air gap field, a constant saturation level and under disregarding of the current displacement and additional iron losses.

The used complex space vectors definitions apply according KOVACS [4]. All variables and parameters are normalized (per-unit) sizes. The usual reference values (nominal values, synchronous speed) [5] were used for scaling.

$$
T_{M}=\omega_{1 n} \frac{J_{M} \omega_{1 n} / p}{M_{B}}
$$

is the corresponding run-up time, which results from the normalized equation of motion.

\section{Estimation of torque and rotational speed}

The estimation of the air gap torque and rotational speed of the DFIG is carried out by means of using a so-called Model Reference Adaptive System (MRAS) [6].

An MRAS consists out of a reference model, which defines the behaviour of the observed system as a reference, and an adaptive model which will adapted to the reference model by an continuous feedback of a derived error signal. Schauder [7] was the very first who presented a MRAS, to estimate the speed of an induction generator (squirrel cage). For the DFIG application the $\underline{u}_{1}, \underline{i}_{1}-\operatorname{model}^{(u)}$ of an induction generator (IG) in the stator-related $(\alpha, j \beta)$ coordinate system serves as reference model.

Eq. (6) is used to calculate the space vector of the stator flux from the measured input variables, the stator voltage $\underline{u}_{1}$ and the stator current $\underline{i}_{1}$.

$$
\frac{d \underline{\hat{\psi}}_{1}^{(u)}}{d t}=\underline{u}_{1}-R_{1} \underline{i}_{1}
$$

Subsequently a first estimated value for the air gap torque of the DFIG can be calculated with Eq. (7), using the esti- mated stator flux vector $\hat{\psi}_{1}^{(u)}$ out of Eq. (6) and the measured stator current vector $\underline{i}_{1}$.

$$
\widehat{m}_{i}^{(u)}=\left|\underline{\hat{\psi}}_{1}^{(u)} \times \underline{i}_{1}\right|=\widehat{\psi}_{1 \alpha}^{(u)} i_{1 \beta}-\widehat{\psi}_{1 \beta}^{(u)} i_{1 \alpha}
$$

In general, open integration of Eq.(6) leads to numeric instability, this can be avoided in a known manner by adding a feedback loop and thereby transforming the integrator into a first order delay function. This operation is valid for the necessary range of bandwidth for state variables of the DFIG. The second, inherent drawback of the $\underline{u}_{1}, \underline{i}_{1}$-model ${ }^{(u)}$ is also well known. Large errors in the estimation of the stator flux and thus of the air gap torque may caused by temperature-dependent variations of the stator resistance $R_{1}$, especially at low generator speed $(n<0.05)$. But in this case it's not relevant, because the DFIG in a variable-speed wind turbine generator application only operates in a narrow speed range of $n \approx$ $(0.7 \ldots 1.3) n_{s n}$ close to its synchronous operation.

For the adaptive model within the MRAS structure serves the $\mathrm{i}_{1}, \mathrm{i}_{2}, \mathrm{n}-$-model $^{(i)}$ of the DFIG in the stator-related $(\alpha, j \beta)$-coordinate system. The adaptable space vector for the stator flux $\underline{\psi}_{1}^{(i)}$ out of the measured input values for stator $\underline{i}_{1}$ and rotor current vector $\underline{i}_{2}$ is calculated by Eq.(8).

$\underline{\hat{\psi}}_{1}^{(i)}=X_{1} \underline{i}_{1}+X_{h} \underline{i}_{2}$

Subsequently, using the measured stator current vector $\underline{i}_{1}$, a second adaptable estimated value for the air gap torque of the DFIG can be calculated according Eq. (9).

$$
\widehat{m}_{i}^{(i)}=\left|\underline{\psi}_{1}^{(i)} \times \underline{i}_{1}\right|=\widehat{\psi}_{1 \alpha}^{(i)} i_{1 \beta}-\widehat{\psi}_{1 \beta}^{(i)} i_{1 \alpha}
$$

If applying the $\underline{i}_{1}, \underline{i}_{2}, n-\operatorname{model}^{(i)}$, it must be noted, that the rotor current vector $\underline{i}_{2}$ always be measured within the specific $(d, j q)$-coordinate system and has to be transformed into the stator related $(\alpha, j \beta)$-coordinate system before using it within Eq.(8).

The required relationships for the transformation are shown in figure 5:
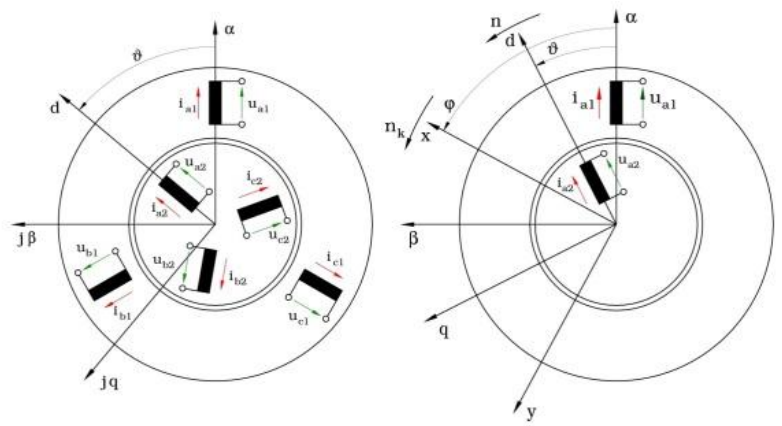

Fig. 5: Equivalent circuit of the DFG and corresponding coordinate systems

$$
\underline{i}_{2}(\alpha, \beta)=\underline{i}_{2}(d, q) e^{j \vartheta}
$$

$\vartheta=p \vartheta_{m}$ therein is the electrical, $\vartheta_{m}$ the mechanical rotation angle of the DFIG rotor relative to the stator position, $p$ characterizes the number of pole pairs. The rotation angle $\vartheta(t)$ is calculated by integrating the normalized rotational speed of the DFIG acc. Eq. (11). 


$$
\frac{d \vartheta}{d t}=n=n_{M}
$$

When applying the proposed solution to estimate the rotational speed of DFIG by means of MRAS structure, the $\underline{i}_{1}, \underline{i}_{2}, n$-model ${ }^{(i)}$ is provided with an estimated value for the speed $\left(\hat{n}_{M}, n_{M}\right)$ delivered by an error-control loop instead of a measured value out of a speed encoder.

$$
\Delta m_{i}=m_{i}^{(u)}-m_{i}^{(i)}
$$

The error value of the air gap torque is generated from the estimated values of air gap torque, therefore the corresponding output values of $\underline{u}_{1}, \underline{i}_{1}$ - and $\underline{i}_{1}, \underline{i}_{2}, n$-model are used according Eq. (12) as input signal for a PI-controller. Then its output signal $\left(\hat{n}_{M}, n_{M}\right)$ corresponds to an estimated, normalized value, which converges to the rotational rotor speed value of the DFIG.

\section{State observer for the mechanical System}

Usually the mechanical subsystem of a drivetrain can be sufficiently modelled as a multi mass oscillator with rigid masses and mass-less spring-damper links. This is also valid for drivetrains within wind turbines applications.

At least for controller design purposes, its relevant characteristics can mostly adequate represented by a linear twomass rotary oscillator with the primary and secondary flywheel masses $\mathrm{J}_{\mathrm{M}}$ (generator side) and $\mathrm{J}_{\mathrm{A}}$ (wind rotor side) both linked by an elastic shaft with the torsional stiffness parameter $c$ and damping coefficient $d$ (see figures $3 \& 4$ ).

In order to estimate state variables of this system, beside the DFIG observer, a second observer is designed, dedicated for the two-mass rotary oscillator. It should be noted, that an observer basically must be supplied with the same input variables as the real system under control.

The first input variable of the two-mass rotational oscillator model is the air gap torque $m_{i}$, supplied by the MRAS model of the DFIG. For the second input variable $\mathrm{m}_{W}$, which is not measurable at all and includes the torque produced by the wind rotor due to aerodynamic effects, a simple but efficient disturbance model according Eq. (13), [8] is added.

$$
\frac{d m_{w}}{d t}=0
$$

Now it's possible to interpret the load side torque as a new state variable and merge it with the model of the two-mass system.

The Luenberger observer error is not calculated, as usual within encoder based control schema, from the measured rotational speed $n_{M}$ and the estimated speed $\hat{n}_{M}^{(m e c h)}$ generated by the observer model itself, but here the estimated value $\hat{n}_{M}^{(e l)}$ provided as an output from the MRAS of the DFIG was used, instead of the measured value $n_{M}$.
Thus the designed observer of the two-mass rotary oscillator is described by the following equation:

$$
\begin{aligned}
& \frac{d}{d t}\left[\begin{array}{c}
\hat{n}_{M} \\
\hat{m}_{W e l} \\
\hat{n}_{A} \\
\hat{m}_{w}
\end{array}\right] {\left[\begin{array}{cccc}
0 & -\frac{1}{T_{M}} & 0 & 0 \\
\frac{1}{T_{c}} & 0 & -\frac{1}{T_{c}} & 0 \\
0 & \frac{1}{T_{A}} & 0 & -\frac{1}{T_{A}} \\
0 & 0 & 0 & 0
\end{array}\right] \cdot\left[\begin{array}{c}
\hat{n}_{M} \\
\hat{m}_{W e l} \\
\hat{n}_{A} \\
\hat{m}_{w}
\end{array}\right] } \\
&+\left[\begin{array}{c}
\frac{1}{T_{M}} \\
0 \\
0 \\
0
\end{array}\right] m_{i}+\left[\begin{array}{c}
k_{M} \\
k_{W e l} \\
k_{A} \\
k_{w}
\end{array}\right]\left(\hat{n}_{M}^{(e l)}-\hat{n}_{M}^{(m e c h)}\right)
\end{aligned}
$$

Eq. (14) includes different normalized time constants:

$$
T_{M, A}=\omega_{1 n} \frac{J_{M, A} \omega_{1 n} / p}{M_{B}}
$$

two run-up times Eq.(15), one for the generator together with specific parts of the other drivetrain components and one for the wind rotor side, dominated by its big inertia, another one according Eq. (16) for the equivalent shaft model with the rotational stiffness parameter $c$.

$$
T_{c}=\frac{p M_{B}}{c}
$$

The Luenberger observer design is done by conventionally pole placement [8] techniques. Based on the eigenvalues of the observed system, which are a double pole in the origin of the complex plane and a complex conjugate pole pair, belonging to the uncontrolled characteristic oscillation behaviour of the drivetrain, the following eigenvalue configuration of the observer is a proven adjustment in terms of resulting dynamics and robustness:

$$
\begin{aligned}
& s_{B 1,2}=\frac{1}{\sqrt{2} T_{B}}(-v \pm j) \\
& s_{B 3,4}=\omega_{0}(-v \pm j)
\end{aligned}
$$

Therfor $\omega_{0}$ is defined as the related natural frequency of the two-mass oscillatory system and $s$ as the Laplace variable. By introduction of the two observers parameters $T_{B}$ and $v$ the process of pole placement becomes physically descriptive. While the normalized observer time constant $T_{B}$ is a measure for the dynamic of the observer, the parameter $v$ defines the damping of transient response. For $v=1$ the so-called natural damping $d=$ $\sqrt{2} / 2$ is obtained, which results in a transient response without overshoot.

The feedback coefficients can be computed, by means of the characteristic polynomial of the observer, as a function for the pole placement [3]. 


\section{Results of test rig measurements}

The presented estimation algorithms and state controller for active rotary oscillation damping have been implemented on a digital signal processor (DSP) and tested extensively on a laboratory test rig.

To avoid disturbance by EMC and to achieve a high signal to noise ratio, also a new measuring technique for electrical quantities was introduced which uses analoguefrequency-analogue conversion with an optical transmission of impulse pattern to the corresponding receiver units near the DSP board [9].

The test rig consists essentially of two inverter-fed, fieldoriented controlled, four-pole $7.5 \mathrm{~kW}$ induction machines. Both machines are coupled via a flexible steel shaft. The resulting two-mass rotary oscillator has the natural frequency $f_{0}=19.6 \mathrm{~Hz}$ and the moments of inertia $J_{A}=$ $J_{M}=0,06 \mathrm{~kg} \mathrm{~m}^{2}$.

The first IG configured as DFIG can either operate in two modes, FOC with PI-controller or sensorless with state controller, the second machine serves as a load application unit and operates in torque-controlled mode.

For accurate measuring of the rotational speeds $n_{M}(t)$, and $n_{A}(t)$, as well as the air gap torque $m_{i}(t)$ and the shaft torque $m_{W e l}(t)$, both machines are equipped with appropriate, high resolution incremental sensors.

The quasi "measured" air gap torque of the DFIG is determined by Eq. (18) from the corresponding measured rotational speed $n_{M}(t)$ or $n_{A}(t)$ and the measured shaft torque $m_{W e l}(t)$, using a precise torque-meter.

$$
m_{i}(t)=T_{M} \frac{d n_{M, A}(t)}{d t} \pm m_{W e l}(t)
$$

All values presented in the following figures are normalized, therefore the results are relative universally valid.

Figure 6 shows the experimental results for measured and estimated shaft torque $m_{W e l}(t)$, measured and estimated load speed $n_{A}(t)$, "measured" and estimated air gap moment $m_{i}(t)$ of the DFIG for a sequence of stepwise changes in load torque.

Here the DFIG operates in encoder based field-oriented control with PI-controller, additionally active and reactive power are controlled too, corresponding to a wind turbine application in principle.

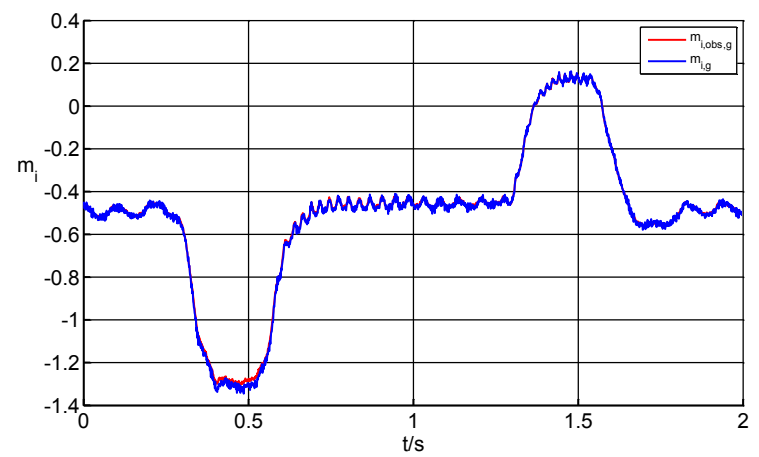

Fig. 6a: Measured and estimated DFIG air gap torque $m_{i}(t)$

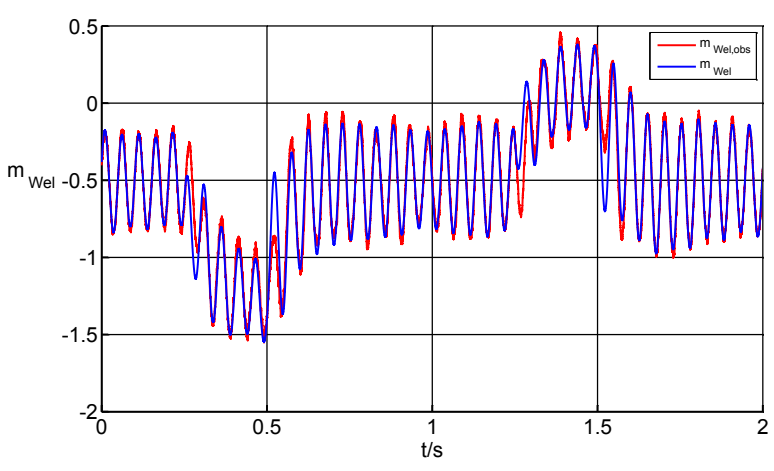

Fig. 6b: Measured and estimated shaft torque $m_{W e l}(t)$

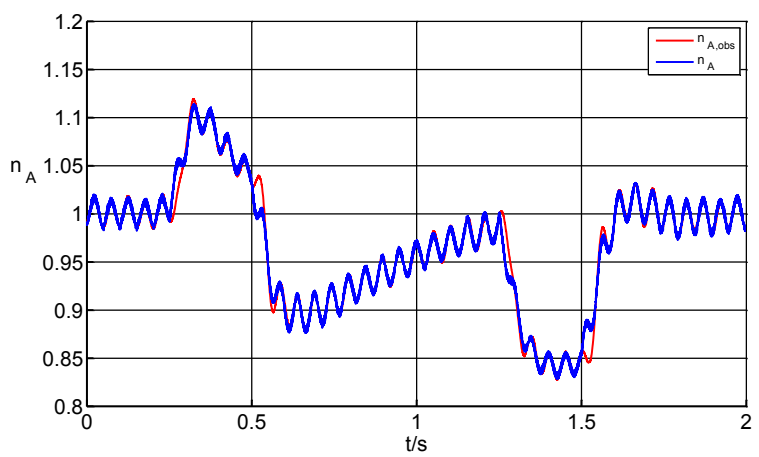

Fig. 6c: Measured and estimated load side speed $n_{A}(t)$

Fig. 6: DFIG with classic FOC and PI-controller structure, stepwise change in load torque, sequence:

$m_{W}^{*}=-0.5 \rightarrow-1.1 \rightarrow-0.5 \rightarrow+0.1 \rightarrow-0.5$ setpoint: $p_{1}^{*}=f\left(m_{w, o b s}, n_{A, o b s}\right) ; q_{1}^{*}=0$

Figure 7 presents the corresponding time responses when the DFIG operates sensorless with state controller for active damping.

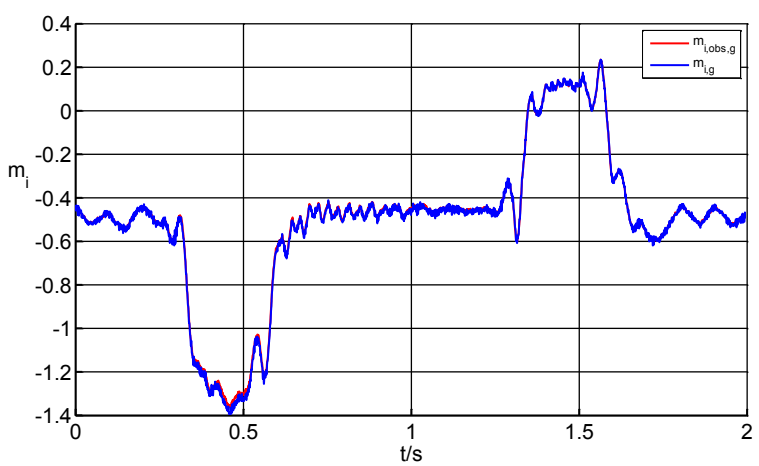

Fig. 7a: Measured and estimated DFIG air gap torque $m_{i}(t)$

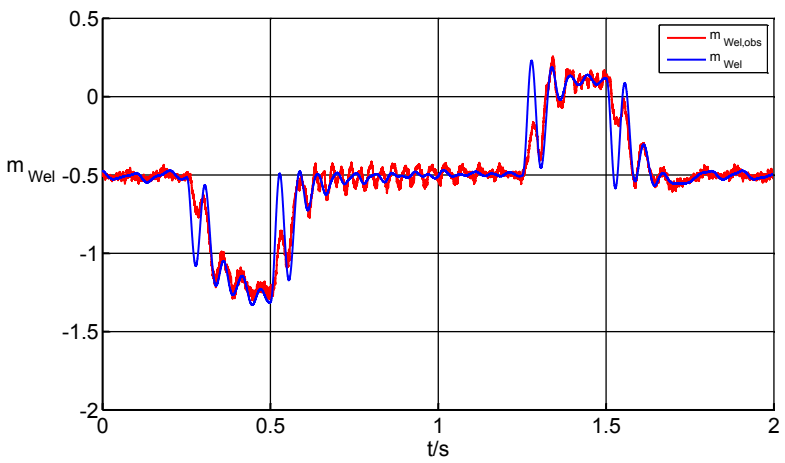

Fig. 7b: Measured and estimated shaft torque $m_{W e l}(t)$ 


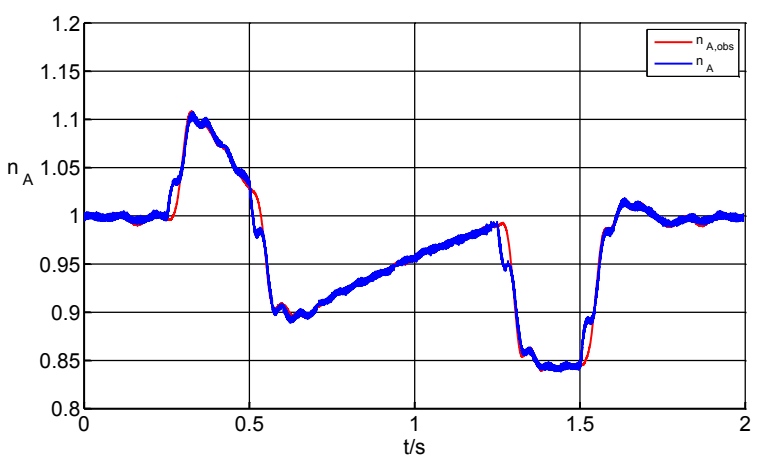

Fig. 7c: Measured and estimated load side speed $n_{A}(t)$

Fig. 7: DFIG sensorless FOC \& state controller, active damping, stepwise change in load torque, sequence:

$m_{W}^{*}=-0.5 \rightarrow-1.1 \rightarrow-0.5 \rightarrow+0.1 \rightarrow-0.5$

setpoints: $p_{1}^{*}=f\left(m_{w, o b s}, n_{A, o b s}\right) ; q_{1}^{*}=0$

In the classical field-oriented control with encoder based PI-controller each step change in the load torque $m_{W}(t)$ results in weakly damped oscillations of $m_{W e l}(t)$, which leads to corresponding characteristic time responses of the DFIG rotor and load side speed $\left(n_{M}(t), n_{A}(t)\right)$.

Operation with the sensorless state controller shows, that the vibrations in the shaft torque $m_{W e l}(t)$ can almost completely be eliminated. Additionally it is quite obvious by comparing measured and estimated time responses that the presented estimators work with high dynamical accuracy for all DFIG an drivetrain state variables.

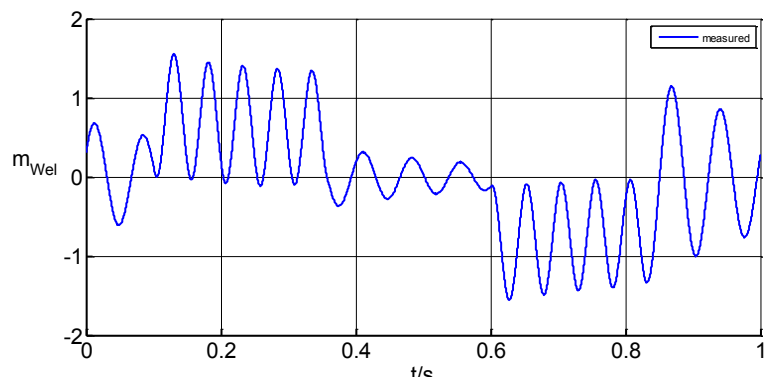

Fig. 8a: Measured shaft torque $m_{W e l}(t)$ with conventionell encoder based FOC and PI-controller structure

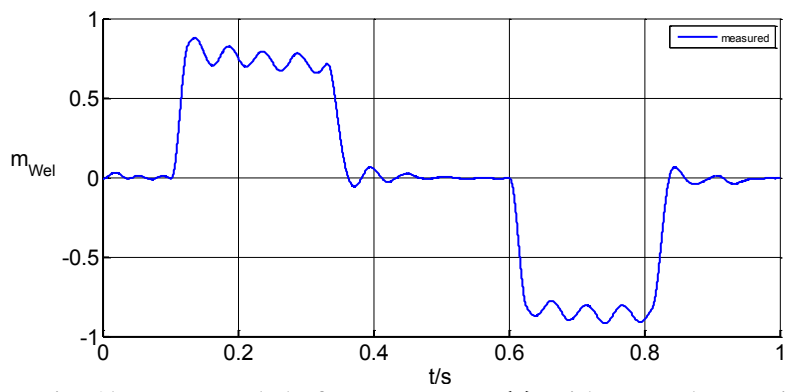

Fig. 8b: Measured shaft torque $m_{W e l}(t)$ with sensorless activ damping and state controller

Fig. 8: Comparison of rotary oscillations: DFIG with FOC \& PIcontrol vs. sensorless state controller with active damping, stepwise change of speed setpoints, sequence:

$$
n^{*}=0.1 \rightarrow 1.0 \rightarrow 0.1
$$

idling with $m_{W}=0$ (no external loads)

Figure 8 shows the time response of the shaft torque $m_{W e l}(t)$ during acceleration and braking due to rotational speed setpoint changes of the DFIG $n^{*}(t)$ with PIcontroller in comparison to sensorless state controller.
For this purpose the speed setpoint is changed stepwise. Again, oscillations in the shaft torque $m_{W e l}(t)$ can be predominantly avoided, without restrictions within the dynamic of setpoint response of the entire control system.

\section{Conclusions}

To illustrate the performance of the new combined observer concept, the investigations were carried out with distinctive test signals, which are commonly used for controller synthesis. Thus it is generally ensured, that the presented system delivers the same quality of results also in wind turbine application with more stochastic load characteristics.

Furthermore the analysis and the tests have been shown, that, in order to achieve a very accurate estimation of the air gap torque $m_{i}(t)$ and the rotational speed $n_{M}(t)$ of the DFIG, it is recommended to consider the saturation dependency of the stator main inductance respectively stator main reactance $X_{h}=f\left(\psi_{h}\right)$ during operation.

Finally it should be noted, further investigations on the test rig prove, that the presented sensorless state controller works even at very low speed $\left(n_{M}=0.02\right)$, parametervariations of $\pm 10 \%$ degrade the active vibration damping results only slightly and the estimator works sufficiently even during grid events [10].

\section{References}

[1] Kelber, C.: Aktive Dämpfung der doppeltgespeisten Drehstrommaschine, Diss. TU Braunschweig 2000

[2] Beckert, U.: Theorie des dynamischen Verhaltens der doppeltgespeisten Asynchronmaschine mit Berücksichtigung der Stromverdrängung im Läufer. Forsch.-Ber. des IfE der TU Bergakademie Freiberg 2003

[3] Goslar, M.: Ein Beitrag zur anwendungsorientierten Zustandsregelung elektrischer Hochleistungsantriebe, Diss. TU Clausthal 1998

[4] Kovac, K.P.; Racz, I.: Transiente Vorgänge in Wechselstrommaschinen. Bd. 1 und Bd. 2; Verlag der Ungarischen Akademie der Wissenschaften, Budapest 1959

[5] Pfaff, G.: Regelung elektrischer Antriebe. Bd. 1; R. Oldenbourg Verlag, München-Wien 1994

[6] Cardenas, R.; Pena, R.; Proboste, J.; Asher, G.; Clare, J.: MRAS Observer for Sensorless Control of Standalone Doubly Fed Induction Generators. Proc. IEEE Trans. On Energy Conversion Vol. 20, No.4, pp 710-718, Dec. 2005

[7] Schauder, C.: Adaptive Speed Identification for Vector Control of Induction Motors without Rotational Transducers. IEEE Trans. Industry Appl., Vol. 28, 1992, No. 5, pp. 1054-1061

[8] Föllinger, O.: Regelungstechnik, 8. Aufl.; Heidelberg: Hüthig-Verlag 1994

[9] Beckert, U.; Neuber, W.: Drehmoment-Beobachter für Asynchronmaschinen, Antriebstechnik 38 (1999); Heft 9, S. $79-83$

[10] Wenske, J.; Beckert, U.: Voltage-induced stresses during Low Voltage Ride Through (LVRT) in the drive train of wind turbines with DFIG, 2012 ICREPQ, Santiago de Compostela (Spain) 